\title{
Justified Belief and Just Conviction
}

\author{
Clayton Littlejohn
}

King's College London

Abstract: When do we meet the standard of proof in a criminal trial? Some have argued that it is when the guilt of the defendant is sufficiently probable on the evidence. Some have argued that it is a matter of normic support. While the first view provides us with a nice account of how we ought to manage risk, the second explains why we shouldn't convict on the basis of naked statistical evidence alone. Unfortunately, this second view doesn't help us understand how we should manage risk (e.g., the risk of violating rights against wrongful conviction) and faces counterexamples of its own. I shall defend an alternative approach that builds on the strengths of these two accounts. On the approach defending here, it is objectively suitable to punish iff we know a defendant to be guilty. To determine what is consistent with procedural justice and to determine what we prospectively ought to do, we need to think about the risks we face of deviating from this objective ideal.

Forthcoming in J. Robson and Z. Hoskins (ed.), Truth and Trial. Routledge.

\section{Introduction}

Let's begin with Smith's (2018) question. When, he asks, does evidence suffice for conviction? An increasingly popular answer is that it does so when it makes it sufficiently probable that the defendant is guilty (Probable Guilt). ${ }^{1}$ Smith's answer is that it does so when it provides normic support for this belief (Normal Guilt). ${ }^{2}$ Cases of naked statistical evidence best lay bare the difference between these approaches, so we shall discuss these cases. Smith is right to reject Probable Guilt, but I fear that Normal Guilt is subject to counterexamples of its own. I shall present one in $\$ 2$ and introduce my alternative to these accounts in $\$ 3$.

An important part of the disagreement between Smith and the defenders of Probable Guilt is a disagreement about how to rightly handle risk. Smith's account of epistemic justification is pitched as an alternative to the familiar 'risk minimisation' picture of justification according to which beliefs are justified when the risk of error isn't too great. Because Smith's account of the standard of proof preserves a connection between meeting the standard of proof and having beliefs that are, according to his theory, justified, Normal Guilt commits us some claims about the connection between just conviction and risk that I think are problematic. While I think that he gets the cases of naked statistical right, I fear that the resultant view he offers to explain these verdicts clashes with our best approach to how we ought to manage risk. My view is designed to preserve the connection between the justification of belief and just conviction and I believe that it fits better with our best views about how we ought to deal with risky situations given our views about the rights of defendants.

Before we turn to the discussion of naked statistical evidence, let me say something about the disagreements at issue. Like Smith, I think that our theories of justification should inform our account of the standard of proof. And I shall assume that the guilty verdict results in a just conviction iff the standard of proof is met. It should be noted that when Smith asks about the sufficiency of evidence, however, he's asking a practical question, not (merely) an epistemic one. The question presupposes that there's a kind of evidential support that determines whether a conviction is just or not. It just so happens that his theory of when evidence suffices for this practical purpose, it is the evidence that determines whether our beliefs are justified. For reasons

\footnotetext{
${ }^{1}$ For defences of this approach, see Hedden and Colyvan (2019), Krauss (forthcoming), Lempert (1977), Papineau (forthcoming), Ross (forthcoming), and Steele (MS).

${ }^{2}$ A body of evidence $\mathrm{E}$ provides normic support for $p$ iff the E-worlds in which $p$ is true are more normal than any E-worlds in which $\sim p$.
} 
that I shall discuss below, I have some deep reservations about the presuppositions of Smith's question, but I do think that he's right that our theory of the standard of proof should accommodate this idea:

Weak Justification: We should not convict unless the jury has justification to believe that the defendant is guilty. ${ }^{3}$

This gives us a useful way to test proposals about the standard of proof. If a theory says that we ought to convict without justification or we ought to convict without what the theory says is required for justification, we have a good reason to reject that theory. As I see it, the best arguments for Probable Guilt don't support the idea that we ought not convict without justification and the counterexamples to Normal Guilt show that we ought to convict without justification as that theory conceives of it. My alternative knowledge-centred view hopefully doesn't suffer from these problems.

\section{Probable Guilt}

Let me briefly explain why Probable Guilt might seem plausible and why this appearance is misleading. The jury has to make a decision under uncertainty and we might frame their decision problem like this:

The Veritist's Decision-Matrix

\begin{tabular}{|l|l|l|}
\hline & Guilty $(g)$ & Not Guilty $(\sim g)$ \\
\hline Convict & good & very bad \\
\hline Don't Convict & bad & neutral \\
\hline
\end{tabular}

Since we should (in some sense) maximise expected choiceworthiness, we can see why we shouldn't convict unless it's highly probable that the defendant is guilty. By the same logic, we should convict when the probability is sufficiently high. Those who shoulder the unhappy burden of having to decide whether to convict can take some small comfort in the fact that we can offer them simple rules, simple matrices, and simple sets of choices so that they can be confident that they made the right choice if they choose to convict in a case like this:

\section{Prisoners}

The defendant is one of the 100 prisoners who were exercising in the yard. On that afternoon, 99 of the prisoners suddenly put into action a plan to attack a guard. In addition to the 99 assailants, there was one more prisoner who was in the yard. He knew nothing of the plan or the attack as it took place. (Even complicated attacks involving lots of assailants might be difficult for bystanders to notice.) You have no further information available to help you determine whether the defendant took part in the attack and you have to decide whether to convict the defendant on the basis of the information that's been provided (Redmayne (2008)).

The problem with this verdict, Thomson says, is that we should only convict if, "we can be very sure of having a guarantee" (1986: 215). We don't have that in this case. This fits with my intuitions, but what about the decision-theoretic rationale for Probable Guilt? Why should we care about anything but the probabilities?

Here's why. These were our assumptions when we framed the decision-problem:

A1. The outcome < convict, guilty $>$ is good.

\footnotetext{
${ }^{3}$ See Littlejohn (2012, forthcoming).
} 
A2. The outcome < convict, not guilty $>$ is the worst outcome.

A3. The outcome $<$ don't convict, guilty $>$ is bad.

A4. The outcome < don't convict, not guilty $>$ is neutral. ${ }^{4}$

Consider (A3). Why should we assume that this outcome uniformly has negative valence? According to (A3), the practice should see the relevant outcome (i.e., <don't convict, guilty $>$ ) as bad however it is brought about. This seems wrong. A jury might convict on the basis of evidence that would lead most reasonable people to conclude that the defendant is innocent. We might think that (in a sense) this is bad regardless of whether the defendant is guilty or innocent. Once we see this and we see that neither < convict, guilty $>$ nor $<$ don't convict, guilty $>$ have uniform valence, we can see why someone might be sceptical of the decision-theoretic rationale offered in support of Probable Guilt.

Let's connect this to Thomson's point about the guarantee. The criminal trial should be subject to a kind of norm, one that regulates the practice so that the jury's guilty finding can be seen as fit for its function. Like Duff, I think the guilty verdict can only fulfil this function when it can serve as, 'an institutional analogue of a moral accusation' (1986: 116). It is constitutive of reaching a good or neutral outcome by means of a guilty verdict that we meet the normative conditions necessary for blaming them for wrongdoing. And this requires that we don't blame or deliver the guilty verdict unless the right epistemic condition is met. The source of this requirement is not itself epistemic, but it imposes epistemic standards nonetheless. ${ }^{5}$ This, I submit, requires that the jury can believe with justification that the defendant has acted badly. ${ }^{6}$ But this requires that they meet the condition imposed by Weak Justification. In brief, this is my objection to the decision-theoretic argument for Probable Guilt. A crucial assumption in the argument for Probable Guilt was that we could first assign value to the outcomes that figured in the veritist's decision-matrix without taking account of the epistemic position of the jury. But we cannot. This is because we cannot say whether the outcome was good unless we know if the jury met the epistemic conditions necessary for holding the defendant to account.

\section{Normic Support}

Normal Guilt was designed to explain why cases like Prisoners differ from cases in which we have, say, experiential grounds for believing someone to be guilty. The rough idea is this. Were it to look as if the defendant was committing a crime and were that appearance to be misleading, we would find ourselves in an abnormal situation, one that called out for explanation. We would have normic support for believing the defendant to be guilty. If, however, we were to form a false belief in a case in which our belief is based on naked statistical evidence, this wouldn't be any indication that the situation was abnormal. Since no explanation of the error would be called for, we lack normic support and lack justification. So, given Weak Justification, we shouldn't convict.

While Normal Guilt issues the right verdict in Prisoners, it delivers the wrong verdict in this case:

\section{Preface Prisoners}

\footnotetext{
${ }^{4}$ Mind you, there are the messy and neglected questions about the prior probabilities we ought to have concerning the guilt of the defendant that need attention. See King (MS).

${ }^{5}$ I hope this responds to some of Backe's (forthcoming) concerns about trying to appeal to epistemic considerations to solve legal puzzles. My view isn't that the epistemic considerations taken in isolation from further normative considerations settle the issue. My view is that the further normative considerations give us reasons that really matter for meeting epistemic standards. It also is intended to address the concerns about epistemic fetishes raised by Enoch, Fisher, and Spectre (2012) and Papineau (forthcoming). It's not fetishistic to care about whether we have standing to blame in this process if the finding of guilt is Duff's institutional analogue of a moral accusation. ${ }^{6}$ For defence, see Adler (2002) and Buchak (2004).
} 
The defendant is one of the 100 prisoners who were exercising in the yard. On that afternoon, a mob of prisoners suddenly put into action a plan to attack a guard. In this trial, as with the 99 other trials, the prosecution uses the 'right' kind of evidence to secure a conviction (e.g., multiple eyewitnesses, CCTV footage, taped confessions, etc.). Once the trial is over and each prisoner is convicted and sentenced, we learn from an informant that precisely one of the prisoners in the yard had been framed, but the informant isn't able to identify the innocent person before he disappears.

There's no possible world in which each proposition in an inconsistent set is true, so there is no normal world in which each is true. So, we cannot have normic support for believing the members of such a set. Provided that we have justification to believe that we are mistaken in one of these cases, Normal Guilt says that we would lack justification to believe some or all of the defendants are guilty. Normal Guilt implies that we either lack justification to believe in each case that the defendant is guilty or that we have it in some but not others. It would be 'too externalist' to say that only some of these beliefs are justified when there is no discernible difference in the kind of evidence we have in each of the cases and that it would be 'too sceptical' to say that we would lack justification to believe in each of the cases once we had justification to believe that an error was made (Dutant and Littlejohn forthcoming b). It would be too dogmatic to deny or suspend judgment on whether an error is made since the informant might bring friends, might be an obvious epistemic superior, etc. Given Weak Justification, we now face the worry that Normal Guilt says (in effect) that all the prisoners must be freed.

To see why this is a counterexample to Normal Guilt, it's helpful to think about how much we can know prior to receiving the informant's testimony and after receiving it. Suppose that we judge initially (i.e., before we hear from the informant) using the 'right kind of evidence' (e.g., CCTV footage, a taped confession, eyewitness accounts) that the defendant is guilty and suppose that she is guilty. In this case, we can know the defendant to be guilty. And what goes for this case, goes for each of the cases in which the belief about the defendant's guilt can be based on this same kind of evidence. (Obviously, we cannot know in the one case where the defendant is innocent.) How much of this knowledge could we retain once we hear from the informant? Well, we cannot retain knowledge in the one case in which we were mistaken in our belief, but I would think that nothing that the informant reveals shows that there is any interesting threat to the knowledgestatus of any particular belief. The relevant belief, for example, could be safe or sensitive. If, in keeping with the judgment that the belief was knowledge, we were to say that it wasn't a matter of luck that we got it right initially, it wouldn't be right to say that it's now a matter of luck that, say, we came to correctly believe that the defendant was guilty given the evidence that we had in the trial. If we set up the case the right way, I think it's possible that we know initially in each case involving a guilty person that the person is guilty and that we can retain this knowledge even after the informant testifies.

What does this tell us about rational belief? Given how much knowledge we have and how probable it is that we have this knowledge in each case, I would think we have rational belief in the cases where we have knowledge and it's so overwhelmingly likely that we have this knowledge. It meets the epistemic condition necessary for properly holding someone responsible. And this is

\footnotetext{
${ }^{7}$ Defenders of Normal Guilt might say that they aren't offering a theory of when we can justly keep people locked away, but we can imagine variants of this case in which this kind of informant reveals something about a series of verdicts that are about to be decided.
} 
why Normal Guilt is mistaken. We don't need normic support to know and we know that we can be highly confident that we have knowledge even when we're certain that it is missing. ${ }^{8}$

It's a selling point of Smith's (2016: 20) view of justification that it predicts that we can have pairs of beliefs where one belief is justified, the second isn't, but the second is more probable. This is why he thinks that it's possible for testimony or perceptual experience to justify a belief even if statistical evidence isn't. He rejects the risk-minimisation picture of justification. I fear that without finding some room in our theory of how to manage risk, we'll run into trouble.

Consider Prison A and B. No naked statistical evidence was used in convicting any of the prisoners. Each prisoner was convicted in accordance with the standards imposed by Normal Guilt. Even if the prisons contain the same number of prisoners, this set up doesn't tell us which of these has a higher evidential probability if we combine all the evidence together:

a. Each prisoner currently held in Prison A is guilty.

b. Each prisoner currently held in Prison B is guilty.

Suppose, as seems possibly in Smith's framework, that the following conditions hold. The wardens of the two prisons only have evidence pertaining to the prisoners in their prisons. The wardens distribute their credences equally when it comes to propositions about the guilt of the prisoners in their prisons and how likely it is that they know these prisoners to be guilty, but while the warden of Prison A rationally assigns very high degrees of confidence to these propositions (i.e., .97 and .95 respectively), the warden of Prison B rationally assigns lower degrees of confidence to the relevant counterpart propositions (i.e., .9 and .86). If they were told by an infallible informant that one prisoner in their prison is guilty, their posterior credences in these propositions would still be uniform.

Suppose that while the warden of Prison B gets no new information, a perfectly reliable informant tells the warden from Prison A that precisely one prisoner in Prison A is innocent. Upon learning this, it seems that he ought to increase his confidence in the guilt of each prisoner and his confidence for each prisoner that he knows that prisoner to be guilty. This information seems epistemically beneficial. Normal Guilt, however, implies that while the warden of Prison B can continue believing each prisoner in her prison is guilty, the warden of Prison A has to suspend judgment when it comes to the guilt of each prisoner.

This is counterintuitive. We need to introduce something to manage risk. Suppose that our evidence just consists of the evidence that these two wardens have and that our credences about guilt, what we can know, etc. match theirs. Consider:

\section{Prisoner Transfer}

Prisons A and B catch fire. We have three options: (i) free all the prisoners, (ii) move the Prisoners from A to Prison $\mathrm{C}$ and free the prisoners in $\mathrm{B}$, or (iii) move the Prisoners from $\mathrm{B}$ to $\mathrm{C}$ and free the Prisoners in A.

We know that Prison A contains one innocent prisoner. We're nearly certain but don't know that $\mathrm{B}$ contains many more innocent prisoners. We have to decide which prisoners to continue to punish and which ones to set free. In this case, we should opt for (ii). We cannot reach this verdict if we accept Normal Guilt. According to Normal Guilt, we are like the warden of Prison A in that our knowledge of the existence of the innocent prisoner in A ensures that we lack justification to believe of any prisoner in A that this prisoner is guilty. Thus, given Weak Justification, we could not be in favour of continued punishment. We can, according to Normal Guilt, continue to justifiably believe of each prisoner in B that they are guilty even though we're much more certain that there are many more innocent prisoners in B than the one innocent prisoner in A. While I

\footnotetext{
${ }^{8}$ For an introduction to the preface, see Makinson (1965). For similar views about rational belief in preface cases that don't just assume the Lockean View, see Dutant and Fitelson (MS), Dutant and Littlejohn (forthcoming), Littlejohn (forthcoming b), and Worsnip (2016). For dissenting views, see Adler (2002) and Ryan (1991, 1996).
} 
would agree that if we lacked justification to believe that a prisoner was guilty, that would give us a decisive reason to free them, we don't have decisive reason to free all the prisoners or to free all the prisoners from Prison A.

What can we take from this? The right verdict about Prison Transfer seems to tell us two things. Assuming Weak Justification, we learn from this case that (a) we ought (in some sense) to punish individuals even if in doing so we know that we'll punish one innocent person and (b) we should sometimes see that we have more reason to respond to expected objective wrongfulness than known objective wrongfulness. Given these assumptions, we can construct an argument against Normal Guilt and use them to help find a plausible alternative.'

\section{Knowledge and the Standard of Proof}

Let's consider a view that explains the differences between cases in which we have experiential grounds for our beliefs, Prisoners, and Preface Prisoners:

Known Guilt: A jury ought to convict the defendant iff the jury knows the defendant to be guilty. ${ }^{10}$

In Prisoners, we cannot know that any of the guilty prisoners are guilty, but we can know that many of them are in Preface Prisoners. Known Guilt tells us that the latter is normatively similar to the humdrum cases where we have fallible experiential grounds for our beliefs and that the former is not because of the difference in the prospect for acquiring knowledge in these cases.

While I have considerable sympathy for this view, it faces objections. I'll discuss two. First, some object to its handling of Preface Prisoners on the grounds that it's thought to be implausible that we ought to treat the individuals differently by convicting some but not others. Second, some object to Known Guilt because it introduces a factive standard.

Let's start with the concern about factivity:

... beyond reasonable doubt is less demanding than knowledge

... [P]lausibly a compelling case for a person's guilt can satisfy the legal threshold of beyond reasonable doubt even if the person is innocent. Some false convictions are procedurally correct (Gardiner forthcoming: 8). ${ }^{11}$

\footnotetext{
${ }^{9}$ See Zimmerman (2009) for an argument that the right that a person has against others is limited to the right that they not be subject to certain kinds of risks by the other where the risks that matter here are determined by the agent's evidence. With apologies to Oliver Wendell Holmes, Jr., this view says that your rights begin roughly around where the noses of others begin. In Littlejohn (2012), I argue that this view implies implausible things about rights of self-defence and the duty of reparation. It cannot explain why, for example, we have reparative duties to those who we discover later were wrongfully convicted for crimes they didn't commit. Zimmerman agrees on the implications of his view for reparations, but doesn't agree that this is a decisive objection. It's unclear whether Smith (forthcoming) thinks that the prisoner's rights supervene upon the jury's evidence or whether he really believes in the right against wrongful conviction.

${ }^{10}$ For defence of views on which there is an anti-luck condition on the standard of proof that is at least similar to the one needed for knowledge, see Duff (1986), Littlejohn (forthcoming), Moss (2018), and Thomson (1986).

${ }^{11}$ Like Duff (1986: 110), I think that the criminal trial is an example of imperfect procedural justice. We can specify what the just outcome would have to be without just describing the just procedures that lead to the trial's conclusion. And I think that our practice of reparation reveals that part of a just conviction is that the rights of the defendant, which include a right against wrongful conviction, have not been violated. Neither Gardiner nor Smith seem to accept my argument (2012: 142) for a factive standard on the grounds that only it would ensure that the right against wrongful conviction is not violated by a (putatively) just conviction, so I worry that they might
} 
Part of me wants to challenge this on grounds that the standard for determining whether a conviction is just is factive, but I don't want to rehash this debate because I don't know why Gardiner or Smith don't accept my earlier arguments for a factive standard. ${ }^{12}$ Instead, I shall offer an account that gives Gardiner and Smith at least part of what they want, something that fits with Gardiner's focus on procedural justice.

Gardiner is right that Known Guilt doesn't give us a plausible account of procedural justice. This doesn't trouble me because I deny that each unjust outcome is an instance of procedural injustice. The passage makes me wonder why she takes such an interest in procedural justice. I can imagine two answers. She might be a prospectivist debater, someone who believes that the prospectivist gives the only reasonable reading of normative language. On this view, our perspective (and/or our evidence) wholly determines what we 'ought' to do. Anyone who thinks that facts about guilt or innocence, on this view, subscribe to a mistaken picture of what we ought to do, what is right to do, what is just, and so on. She might instead be a divider who thinks that we should focus on some non-objectivist reading of normative language. If so, she thinks that while there might be a sense in which we 'ought' not punish the innocent or 'ought' to conform to some factive standard, this isn't the reading that we're concerned with. For some reason, she thinks that the debate has to be about the prospective reading of 'ought', one that's concerned with the agent's perspective and evidence. This is more closely related to procedure. ${ }^{13}$

While I reject the prospectivist debater's view, I can respect the desire to give an account of what we prospectively ought to do, so I shall offer an account. One way to state a theory of what we prospectively ought to do is to first state a theory of what we objectively ought to do and then derive the theory of prospective obligation from that. ${ }^{14}$ Known Guilt, to my mind, provides the best theory of what we ought objectively to do. It tells us that we should never convict the innocent but convict when we're in a position to know that someone is guilty and so identifies an ideal that I think better fits with our normative convictions than the implicit account of objective ideals built into the veritist's decision-matrix. If we face the difficult choice of having to convict or not, we can expect that we'll be uncertain whether by convicting we will deviate from the ideal by failing to convict when we can know that the defendant is guilty or by convicting when we aren't in a position to know that the defendant was guilty. Known Guilt tells us what to do in such situations. It tells us to never convict the innocent and to convict whenever we can know someone to be guilty, but for familiar reasons people find this kind of advice unsatisfying and want an account of what we should do in the face of uncertainty.

Luckily, I don't need to invent this theory from scratch. I can appropriate the standard story, draw on Known Guilt to give an account of the objective ideal, and the result will be an account of what we prospectively ought to do and believe that captures what was good about Probable Guilt (i.e., it fits with our best account of the management of risk) and Normal Guilt (i.e.,

ultimately have to deny that defendants have this right (or sever the connection between meeting the standard of proof and securing a just conviction).

${ }^{12}$ One notable exception would be Zimmerman (2009). He embraces the idea that, roughly, an agent's evidence wholly determines what they might permissibly do and what her obligations might be and so denies that we have rights against others that they don't harm us or don't wrongly convict us for crimes we didn't commit on the grounds that such rights would imply the existence of duties that wouldn't supervene upon the agent's evidence. I don't believe Gardiner or Smith embraces this view that, as it were, my rights against you end around where your nose begins.

${ }^{13}$ See Sepielli (2018) for discussion.

${ }^{14}$ We might see Probable Guilt as such a theory. Here is why I prefer Probable Knowledge to Probable Truth. Probable Knowledge explains intuitions that Probable Guilt cannot. It fits with a better theory of what's objectively suitable (i.e., Known Guilt as opposed to some truth-centred alternative). It incorporates the same approach to the management of risk, though it tells us to be concerned with different risks than a truth-centred approach would. 
it explains important distinctions that Probable Guilt cannot). When we face twin normative pressures to promote the goods and avoid promoting the bads, we know that we ought prospectively to do-maximise expected choiceworthiness. We are under twin normative pressures because of reasons, not values. ${ }^{15}$ Fortunately, we can deal with reasons and uncertainty about them in a similar way. ${ }^{16}$ We can consequentialise. ${ }^{17}$ We can capture the normative content of a theory like Known Guilt by representing the responses that go against the (objective) reasons as if such responses bring about bad outcomes. This will give us a way to rank options. It will also tell us how much normatively worse some deviations from an ideal are from others (e.g., whether it is worse to fail to punish those we objectively ought to than it is to punish those we objectively ought not to and how much worse one thing is than the other). Here, we can use probabilistic discounting to determine how expectably bad an option is. What we prospectively ought to do is minimise this expected normative wrongfulness.

Suppose, for example, that it is normatively bad not to convict those we were in a position to know were guilty and normatively worse to convict those who we weren't in a position to know to be guilty. Then, we might represent the jury's decision problem using this matrix:

The Gnostic's Decision-Matrix

\begin{tabular}{|l|l|l|}
\hline & Can know g $(\mathrm{Kg})$ & Cannot know g $(\sim \mathrm{Kg})$ \\
\hline Convict & 0 & -3 \\
\hline Don't Convict & -1 & 0 \\
\hline
\end{tabular}

These numbers represent how bad it is to act against the objective reasons posited by Known Guilt. Given this and the agent's rational credences, we can determine when we ought prospectively to convict. We ought prospectively to do so iff the expected objective wrongdoing of Don't Convict exceeds that of Convict. This happens when it is sufficiently probable that we know the defendant to be guilty.

${ }^{15}$ Readers might wonder why we would need the theory of what we objectively ought to do or believe in addition to this theory of what we prospectively ought to do or believe. The best prospectivist views of obligation seem to be ones that deny that we have rights against others that they don't impose harms upon us, wrongfully convict us, and so on. If what we ought prospectively to do is determined entirely by our evidence and not the evidence of our potential victims, it's hard to see how they could have the right not to be harmed by us since such rights would have no bearing on what we ought prospectively to do. And if they have no such bearing, it seems empty to say that we nevertheless have a duty, say, not to harm them or wrongfully convict them. But, if we want to say that they have such rights and that we have such duties (e.g., in explaining something about duties of reparation, their rights to self-defence, etc.), we might find that it's helpful to have a theory on which we objectively shouldn't convict the innocent, say, or shouldn't objectively harm others without overriding reason to do so. It would be hard to explain why, say, in the wake of wrongful conviction we have a reparative duty to the person wrongfully convicted if all we can say was that it was bad, unfortunate, or unlucky for them to have been convicted by someone who ought to convict them. I think it's useful, in other words, to say that procedural justice is but one part of the just conviction. The just conviction has an objective dimension, too.

${ }^{16}$ This follows the recipe that Lazar (forthcoming) provides for giving a decision-theory for nonconsequentialism, a theory that he thinks provides a good theory of what we prospectively or subjectively ought to do. For a similar but slightly different approach, see Olsen (2018). I explore this further for the case of belief in Littlejohn (forthcoming b) and in Dutant and Littlejohn (forthcoming $b$ ).

${ }^{17}$ See Oddie and Milne (1991) for an explanation as to why we ought to be confident that we can consequentialise and an argument that we ought to use probabilistic discounting to give a theory of what we prospectively ought to do. 
We can give a parallel treatment of belief:

The Gnostic's Belief-Matrix

\begin{tabular}{|l|l|l|}
\hline & Can know g $(\mathrm{Kg})$ & Cannot know g $(\sim \mathrm{Kg})$ \\
\hline Believe & 0 & -3 \\
\hline Don't Believe & -1 & 0 \\
\hline
\end{tabular}

This tells us that we ought to believe a defendant to be guilty if the expected objective wrongdoing of Don't Believe exceeds that of Believe, which it does when the probability that our belief will constitute knowledge is sufficiently high. ${ }^{18}$

That gives us this general account of when we prospectively ought to convict and believe:

Probable Knowledge: A jury ought to believe the defendant

to be guilty and convict iff the probability that the jury can

know the defendant to be guilty is sufficiently high.

This account tells us why we shouldn't believe or convict in Prisoners (i.e., because it is certain that we will violate Known Guilt), why we should in Preface Prisoners (i.e., because it is sufficiently probable that we know and thus the right way of dealing with the risk of violating one half of it is to take the chance of violating the other), and it captures the important dimension of riskmanagement that seemed to be missing from Normal Guilt.

Like Probable Guilt and Normal Guilt, Probable Knowledge tells us that we ought prospectively to treat each defendant the same in Preface Prisoners and Prisoners. But unlike these views, it does this whilst explaining why we ought to convict the defendants in Preface Prisoners but not in Prisoners. (It is highly probable that we know in each case in Preface Prisoners but certain we don't know in Prisoners.)

Smith (forthcoming) will presumably object that Probable Knowledge suffers from the very problem that he thinks arises for Probable Guilt, which is that it implies that we sometimes ought to knowingly convict the innocent:

The evidence against each of these individuals is exactly the same ... Having convicted ... on the strength of this evidence, we are effectively committed to convicting each of these individuals as well. To convict some, and not others, would be deeply unjust. By convicting all 100 individuals, however, we are now guaranteed to have convicted an innocent-we have more convictions than we do crimes. To convict all 100 individuals is tantamount to deliberately convicting an innocent person (forthcoming: 4).

Smith thinks that if we were to convict each of the defendants in Prisoners knowing that one must be innocent, this is morally equivalent to knowingly convicting a particular innocent person in order to bring about some desirable outcome (e.g., by fabricating evidence and convicting someone known to be innocent in order to restore order and calm a frightened community). And if that objection works against Probable Guilt's treatment of Prisoners, it should work equally well against Probable Knowledge's treatment of Preface Prisoners.

Let's flesh out Smith's argument:

${ }^{18}$ Dutant and Fitelson (MS) defend this view of rational belief by appeal to a gnostic epistemic utility theory (i.e., one that takes knowledge and failed attempts at knowing to be the fundamental goods and bads). Littlejohn (forthcoming b) defends it as a theory of rational belief by consequentialising a non-consequentialist knowledge-centred view of what we objectively ought to believe and applying probabilistic discounting on the reasons to conform to knowledge norms to arrive at this view. 
P1. It is wrong to knowingly convict a single innocent person in order to bring about some desirable result.

P2. If so, it would be wrong to knowingly convict a collection of suspects when it is known that this group contains an innocent person.

C1. So, it is wrong to convict a collection of suspects when it is known that this group contains an innocent person.

P3. Probable Knowledge and Probable Guilt imply that it is sometimes permissible to convict a collection of suspects known to contain an innocent person.

C2. Thus, Probable Knowledge and Probable Guilt are mistaken.

What should we make of this argument?

If this argument were sound, it would support this principle:

Capped Convictions: It is never permissible to knowingly punish $\mathrm{N}$ people for $\mathrm{N}-1$ offenses (Littlejohn forthcoming: 13).

It might seem that it's a virtue of Normal Guilt that it's compatible with this principle and a vice of Probable Guilt and Probable Knowledge that it's not. ${ }^{19} \mathrm{I}$ have mixed feelings about appeals to Capped Convictions in a setting in which it is agreed that this is false:

Never the Innocent: It isn't permissible to punish people for crimes they didn't commit.

Smith seems to be saying that it is permissible to convict and punish the innocent, provided that a certain epistemic condition isn't met. As a claim about what is objectively permitted, this seems wrong to me. As a claim about what is prospectively permitted, it seems quite right, but then I don't think that Capped Convictions is true on this prospective reading. I think it's true only on the objective reading.

To see whether Smith's objection to Probable Knowledge is sound in a setting where it's clear that we're talking about what we prospectively ought to do, we need to work out what we should think about rights and risks. I think Smith and I can agree that this is false:

No Risk: It is never permissible to run the risk of convicting an innocent person.

Normal Guilt implies that it is false because it implies that we can convict when we have normic support for our beliefs regardless of whether the defendant is innocent or guilty. Probable Knowledge likewise allows that it can be that we ought prospectively to punish the innocent. The problem that he faces is that the only way that he can deny No Risk and insist on Capped Convictions is if he rejects this principle:

Minimising Risk: When faced with two options both of which run the risk of convicting an innocent person, we can permissibly choose the option that minimises the expected objective wrongdoing associated with the violation of rights.

But Prison Transfer made Minimising Risk seem attractive in the cases like Preface Prisoners and Prison Transfer. Once we deny No Risk, the argument from Minimising Risk to the denial of Capped Convictions is straightforward. So, the best package of views available to someone

\footnotetext{
${ }^{19}$ Smith can argue for Capped Convictions as follows. Assume Weak Justification and Normality. According to Weak Justification, we can only convict a collection of individuals if we justifiably believe of each individual that this individual is guilty. But Normality does not allow that we can simultaneously be justified in thinking each individual to be guilty if we also justifiably believe that at least one of them is innocent.
} 
who denies No Risk and denies Never the Innocent is a view that incorporates Minimising Risk and denies Capped Convictions.

I've explained why I'm not moved by Smith's objection, but I need to find a premise to deny. Since I agree with (P1), I deny (P2). Some of the best reasons I can think of for accepting (P1) don't give us any reason to think that we cannot permissibly convict each of the defendants in Preface Prisoners. If we accept the Kantian injunction against treating a person merely as a means or we accept some restriction that forbids intentionally doing bad things to a person in order to bring about some desirable outcome, we would have our justification for (P1), but neither the Kantian principles nor the doctrine of double effect tells us anything about what we ought to do in Preface Prisoners. ${ }^{20}$ When we punish a group that we are certain contains an innocent person but we don't know which person this is, we neither treat this person merely as a means to some end nor do we intentionally violate this person's rights.

Part of what I find objectionable about Normal Guilt is this. Once we reject No Risk, if were to insist that we can never punish a collection of individuals known or justifiably believed to contain an innocent person, we end up denying Minimising Risk because of what appears to be a strange preference to not run risks when we have certain binary attitudes (i.e., knowledge, justified belief) about violating the rights of unidentified people as opposed to avoiding imposing greater risks upon greater numbers of people. Smith might say that I'm equally committed to strange views of my own, such as the idea that it's okay to knowingly convict the innocent provided that their identity is hidden and not okay to do so when their identity is known.

This is a tricky issue, but in cases like Prisoners and Preface Prisoners, we're thinking about convicting individuals and collections of convictions. The underlying objective theory that serves as the foundation for what we should prospectively do was formulated in such a way as to make it clear that the primary locus of concern is with how we treat the individuals. Everything we want to say about the collections follows on from what we've said about the individuals and how we act in light of their rights and interests. The collections don't have rights and interests to consider in addition to the ones that the individuals have. Objectively speaking, we should convict an individual when we know them to be guilty and shouldn't otherwise. When we're uncertain about whether the relevant objective condition obtains, the way that we prospectively ought to treat this individual is by trying to approximate the objective ideal while being mindful of the way ways that we can fall short of it (i.e., by failing to convict when we objectively should or by convicting when we objectively shouldn't). And given the standard story about risk minimisation, this gives us Probable Knowledge. It matters that no particular person can reasonably object for failing to do what we prospectively ought if we approximate the ideal in the way that Probable Knowledge recommends. They can complain that their rights are violated and that we've failed to do what we objectively ought, but that's a different matter and that kind of complaint can be levelled against Normal Guilt, too. My framework tells us how to register the force of this complaint. We have to concede that we did everything we prospectively ought to do but failed to do what we objectively ought. Reparation is owed.

\section{Conclusion}

Let's return to Smith's question. When does evidence suffice for conviction? In a sense, never. If the guilt or innocence of the defendant doesn't supervene upon the jury's evidence, the jury's evidence doesn't determine what objectively ought to be done or believed. Whether the jury objectively ought to convict depends upon what they can know. In another sense, the evidence suffices for convicting in ways we prospectively ought to when it is sufficiently probable that we know the defendant to be guilty. This view, Probable Knowledge, better captures our

${ }^{20}$ See Aboodi, Borer, and Enoch (2008). 
intuitions about what objectively matters, how we ought to deal with our cases, and fits with our best approach to risk and uncertainty.

\section{References}

Aboodi, Ron, Border, Adi, and Enoch, David. 2008. Deontology, Individualism, and Uncertainty. Journal of Philosophy 105: 259-72.

Adler, J. (2002). Belief's Own Ethics. Cambridge: MIT University Press.

Backes, Marvin. Forthcoming. Epistemology and the Law: Why there is No Epistemic Mileage in Legal Cases. Philosophical Studies.

Buchak, Laura. 2013. Belief, Credence, and Norms. Philosophical Studies 169: 1-27.

Christensen, David. 2004. Putting Logic in Its Place. Oxford: Oxford University Press.

Colyvan, Mark and Hedden, Brian. 2019. Legal Probabilism: A Qualified Defence. The Journal of Political Philosophy 27: 448-68.

Duff, Antony. 1986. Trials and Punishments. Cambridge University Press.

Dutant, Julien and Fitelson, Branden. MS. Knowledge-Centered Epistemic Utility Theory.

Dutant, Julien and Littlejohn, Clayton. Forthcoming. Defeaters as Indicators of Ignorance. In J. Brown and M. Simion (ed.), Reasons, Justification, and Defeat. Oxford University Press.

Dutant, Julien and Littlejohn, Clayton. Forthcoming. Justification, Knowledge, and Normality. Philosophical Studies.

Easwaran, Kenny. 2016. Dr. Truthlove or: How I Learned to Stop Worrying and Love Bayesian Probabilities. Nous 50: 816-33.

Enoch, David, Fisher, Talia., and Spectre, Levi. 2012. Statistical Evidence, Sensitivity, and the Legal Value of Knowledge. Philosophy and Public Affairs 40: 197-224.

Gardiner, Georgi. Forthcoming. Legal Evidence and Knowledge. The Routledge Handbook of the Philosophy of Evidence. Routledge.

King, Zoe Johnson. MS. The Trouble with Standards of Proof.

Krauss, Sam Fox. Forthcoming. Against the Alleged Insufficiency of Statisical Evidence. Florida State University Law Review.

Laudan, Larry. 2011. The Rules of Trial, Political Morality, and the Costs of Error: Or, is Proof Beyond a Reasonable Doubt Doing More Harm than Good?' In. L. Green and B. Leiter (ed.), Oxford Studies in the Philosophy of Law. Oxford University Press.

Lazar, Seth. Forthcoming. Deontological Decision Theory and the Grounds of Subjective Permissibility. Oxford Studies in Normative Ethics. Oxford University Press.

Littlejohn, Clayton. 2012. Justification and the Truth-Connection. Cambridge University Press.

Littlejohn, Clayton. Forthcoming. Truth, Knowledge, and the Standard of Proof in Criminal Law. Synthese.

Littlejohn, Clayton. Forthcoming b. On what we should believe (and when (and why) we should believe what we know we should not believe). In K. McCain \& S. Stapleford (ed.), Epistemic Duties. Routledge.

Makinson, David. 1965. The Paradox of the Preface. Analysis 25: 205-7.

Moss, Sarah. 2018. Probabilistic Knowledge. Oxford University Press.

Nelkin, Dana. 2000. The Lottery Paradox, Knowledge, and Rationality. Philosophical Review 109: 373-409.

Oddie, Graham and Milne, Peter. 1991. Act and Value: Expectation and the Representability of Moral Theories. Theoria 57: 42-76.

Olsen, Kristian. 2018. Subjective Rightness and Minimizing Expected Objective Wrongness. 99: 417-441.

Papineau, David. Forthcoming. The Disvalue of Knowledge. Synthese.

Redmayne, Michael. 2008. Exploring the proof paradoxes. Legal Theory 14: 281-309. 
Ross, Lewis. Forthcoming. Rehabilitating Statistical Evidence. Philosophy and Phenomenological

Research.

Ryan, Sharon. 1991. The Preface Paradox. Philosophical Studies 64: 293-307.

Ryan, Sharon. 1996. The Epistemic Virtues of Consistency. Synthese 109: 121-41.

Sepielli, Andrew. 2018. Subjective and Objective Reasons. In D. Star (ed.), The Oxford Handbook of Reasons and Normativity. Oxford University Press, pp. 784-800.

Smith, Martin. 2016. Between Probability and Certainty. Oxford University Press.

Smith, Martin. 2018. When Does Evidence Suffice for Conviction? Mind 127: 1193-1218.

Smith, Martin. Forthcoming. Against Legal Probabilism. In J. Robson and Z. Hoskins (ed.) Truth and Trial. Routledge.

Steele, Katie. MS. Crime, Punishment, and 'Individualized' Evidence.

Thomson, Judith. 1986. Liability and Individualized Evidence. Law and Contemporary Problems 49: 199- 219 .

Worsnip, Alex. 2016. Belief, Credence, and the Preface Paradox. Australasian Journal of Philosophy 94: 549-562.

Zimmerman, Michael. 2008. Living with Uncertainty. Cambridge: Cambridge University Press. 